\title{
The prevalence of internet gaming disorder among medical students at King Saud University, Riyadh, Saudi Arabia
}

\author{
A cross-sectional study
}

Mohammad I. Al Asqah, Medical Student, Adel I. Al Orainey, Medical Student, Maan A. Shukr, Medical Student, Hassan M. Al Oraini, Medical Student, Yousef A. Al Turki, MBBS, ABFM.

\begin{abstract}

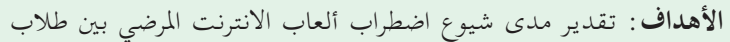

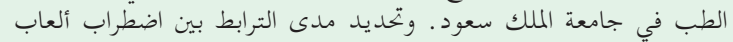

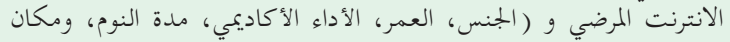

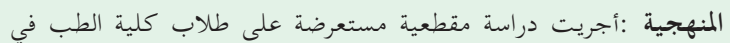

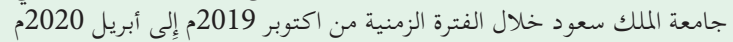

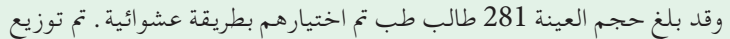

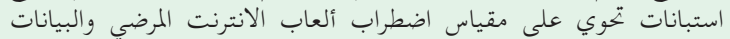

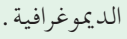

النتائج :كان عدد الردود 228 ردا، نسبة شيوع اضطراب أرداب ألعاب الانترنت

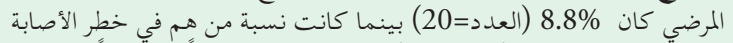

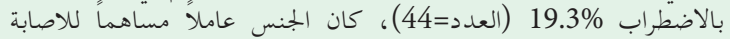

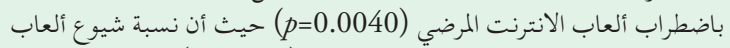

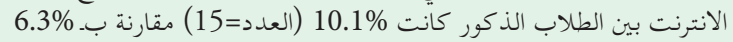

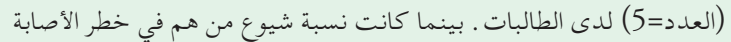

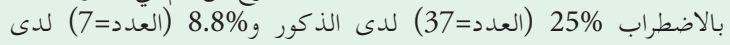
الإناث.

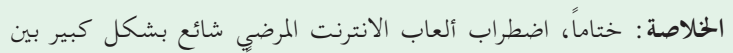

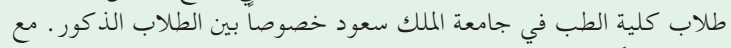

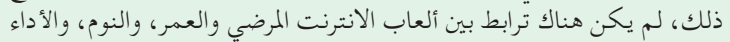

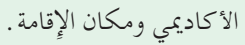

Objectives: To estimate the prevalence of internet gaming disorder (IGD) among King Saud University (KSU), Riyadh, Saudi Arabia medical students and to determine the association of IGD with gender, age, academic achievement, amount of sleep, and accommodation.

Methods: We conducted a cross-sectional study between October 2019 and April 2020 on KSU medical students with a sample size of 281 medical students currently studying at KSU chosen by a stratified proportionate random sampling. The questionnaire contained the IGD short scale and questions eliciting demographic data.
Results: The sample comprised of 228 responses. The prevalence of IGD was $8.8 \%(n=20)$, while $19.3 \%$ $(n=44)$ of the participants were risky gamers. There was a significant association $(p=0.0040)$ between IGD and gender, with $10.1 \%(\mathrm{n}=15)$ of males having IGD compared to $6.3 \%(n=5)$ of females. Additionally, $25 \%(\mathrm{n}=37)$ of males were risky gamers, as compared to $8.8 \%(\mathrm{n}=7)$ of females.

Conclusion: There is a high prevalence of internet gaming disorder among KSU medical students, with higher frequency among males. However, there was no significant association between this disorder and age, sleep, academic achievement, or accommodation.

Keywords: students, medical, video games, internet, Saudi Arabia, prevalence

Saudi Med J 2020; Vol. 41 (12): 1359-1363 doi: 10.15537/smj.2020.12.05584

From the College of Medicine, (Al Asqah, Al Orainey, Shukr, Al Oraini), and from the Department of Family and Community Medicine (Al Turki), College of Medicine, King Saud University Medical City, Riyadh, Kingdom of Saudi Arabia.

Received 25th September 2020. Accepted 21st November 2020.

Address correspondence and reprint request to: Mr. Mohammad I. Al Asqah, College of Medicine, King Saud University Medical City, Riyadh, Kingdom of Saudi Arabia. E-mail:miasqah@gmail.com

ORCID ID: https://orcid.org/0000-0002-1221-6533

Disclosure. Authors have no conflict of interests, and the work was not supported or funded by any drug company. 
$\mathrm{I}$ n 2013, the American Psychiatric Association added internet gaming disorder (IGD) to the 5th edition of Diagnostic and Statistical Manual of Mental Disorders (DSM) as a condition that required further study and investigation. This disorder is indicated when 5 (or more) of the following criteria proposed by the DSM-5 occur for 12 months: i) preoccupation, ii) withdrawal symptoms if gaming is not available, iii) tolerance, iv) unsuccessful attempts to control engaging in internet games, v) loss of interest in hobbies because of internet games, vi) continued extreme use of internet games in spite of knowing its effect, vii) deception of others regarding the amount of time using internet games, viii) use of internet games as an escape from negative feelings, and ix) experience of negative effects on the individual's social life, academic life, or career. ${ }^{1}$ Later in 2018, the World Health Organization (WHO) in its 11th revision of the International Classification of Diseases (ICD-11) classified gaming addiction as a disorder that would be recognized by healthcare providers at the community level and would be seen as a disorder that should be diagnosed and treated. ${ }^{2}$ Research studies have found that some negative characteristics are associated with IGD, such as anxiety, hostility, aggressive behavior, and sleeping problems. ${ }^{3,4}$

Studies suggested that the prevalence of IGD worldwide is estimated to be $3.05 \%, 1.6 \%$ among adolescents 14-17 years old in Europe, and 5.9\% among adolescents in South Korea. ${ }^{5-7}$ In the Middle East, a study was conducted in Ain-Shams University, Egypt on students regarding the prevalence of IGD, where it was estimated to be $9.3 \%$ and $10.9 \%$ among the medical faculty students. ${ }^{8}$ In Saudi Arabia, 2 studies were conducted in the Al-Qassim Region. One was on international secondary school students in the city of Buraydah using the video game addiction scale, where the prevalence was estimated to be $15.8 \% .{ }^{9}$ The second study was conducted on adolescents from the whole Al-Qassim region, investigating both gaming (using the 7-item Gaming Addiction Scale) and stress. The study estimated that $5 \%$ of the students were addicted to gaming. ${ }^{10}$

Our study aims to estimate the prevalence of IGD among medical students at King Saud University (KSU), Riyadh, Saudi Arabia, and to determine the association of IGD with gender, age, academic achievement, amount of sleep, and accommodation.

Methods. A cross-sectional study was carried out between October 2019 and April 2020 at KSU, College of Medicine. The targeted population was medical students from KSU. The study included those who were enrolled in the college curriculum during the time of the data collection with no exclusion criteria. We used the following formula:

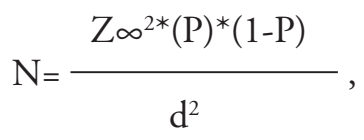

assuming a prevalence of $10.9 \%$, which was estimated based on the prevalence of IGD among medical faculty students with similar sample age and culture in an Egyptian university. ${ }^{8}$ The study required a minimum of 281 participants to estimate the prevalence of IGD with a $4 \%$ degree of precision and a $95 \%$ confidence level, with an added $20 \%$ for the expected non-response rate. The student affairs deanship provided us with a list of students' names, and the participants were selected by a stratified proportional randomizing method according to the distribution of academic year and gender. We contacted group leaders from each year by e-mail, requesting that they send the questionnaire link to the randomly chosen participants from their group. We sent the questionnaire in an electronic form using Google forms to protect the participants' privacy and to reach both male and female students and those who may not have been on campus during the time of the data collection. The questionnaire was divided into 2 sections, with the informed consent agreement on the first page. The first section included demographic questions, which solicited information the participant's age, academic year, gender, academic achievement (specifically, grade point average), amount of sleep (how much the participant has slept per day on average in the last 12 months), and accommodation (whether the participant lives with their family or separately). The second section had a validated Arabic translation of the IGD 9-Item Short Scale which consists of 9 yes-or-no questions; the scale assigns one point for each "yes" answer, where a score of 2 to 4 indicates a risky gamer, and 5 or more indicates a disordered gamer. ${ }^{11}$ The Arabic translator granted us permission for use of the translated scale by e-mail. The original questionnaire was developed for the assessment of IGD based on the criteria suggested by the DSM-5 and has been translated into many language. ${ }^{12-15}$

The Institutional Review Board (IRB) at KSU, College of Medicine approved this study, assigning it the project No. E-19-4423. We acquired informed consent through a statement of consent at the beginning of the first page of the online questionnaire that was approved by KSU-IRB prior to the commencement of the study. To ensure participants' anonymity, we assigned each 
individual a code number for the purpose of the analysis only. We did not give or offer participants any incentives or rewards to participate. The investigators of this study had no conflict of interest.

Statistical analysis. The data analysis software used for this study was IBM SPSS Statistics for Windows, version 21 (IBM Corp., Armonk, N.Y., USA). Descriptive statistics (frequencies, percentages, mean, and standard deviation) were used to describe the categorical and quantitative variables. We used a Chi-square test to determine the significance between the IGD groups and gender. One-way analysis of variance testing was used to test for association between the IGD groups and grade point average (GPA), sleep time, and age. A p-value of $<0.05$ was used to report the statistical significance of the results.

Results. With a response rate of $81.1 \%$, the final sample was comprised of 228 responses with participants ranging from 18 to 25 years of age (mean $=21.15, \mathrm{SD}=1.567$ ) with $64.9 \%$ being male. The sample included more first-year students than students from any other year (27.2\%). Table 1 displays the main socio-demographic characteristics of the subjects.

The prevalence of IGD (5 or more items answered yes) was $8.8 \%$ with $65 \%$ of respondents in their first $(35 \%)$ or second $(30 \%)$ year. Moreover, $19.3 \%$ of the participants were risky gamers (scoring between 2 and 5). A significant association exists $(p=0.004)$ between IGD and gender, with $10.1 \%$ of males having IGD as compared to $6.3 \%$ of females, while $25 \%$ of males were risky gamers, as compared to $8.8 \%$ of females. Table 2 presents the number and proportion of each group separated by gender.

The mean age for the IGD group was 20.95 $(\mathrm{SD}=1.605)$ which was slightly lower than that of the risky gamers (21.11, SD=1.650) and those without IGD (21.19, SD=1.545). The majority of the IGD group was from the first and second years (65\%). There was no significant association between IGD and age $(p=0.800)$. The mean GPA for the IGD group was $4.495(\mathrm{SD}=0.322)$, while the GPA for the risky gamers was $4.392(\mathrm{SD}=0.459)$ and $4.430(\mathrm{SD}=0.465)$ for those without IGD with no significant difference ( $p=0.698)$. The mean sleep time in hours for the IGD group was 7.2 hours $(\mathrm{SD}=1.47)$, while the mean for the risky gamers was 6.66 hours $(S D=1.24)$ and 6.97 hours $(\mathrm{SD}=1.47)$ for those without IGD with no significant difference $(p=0.301)$. Out of the 228 participants, 12 live separately from their family with none of them having IGD and 3 of them being risky gamers.

Item 1 (Have there been periods when all you could think of was the moment that you could play a game?)
Table 1 - Distribution of socio-demographic characteristics of study subjects $(\mathrm{N}=228)$.

\begin{tabular}{lc}
\hline Variable & $\mathbf{n}(\%)$ \\
\hline Age & $21.15 \pm 1.57$ \\
Mean \pm SD & $18-25$ \\
Range & \\
Gender & $148(64.9)$ \\
Male & $80(35.0)$ \\
Female & \\
Year of study & $62(27.2)$ \\
$1^{\text {st }}$ & $45(19.7)$ \\
$2^{\text {nd }}$ & $50(21.9)$ \\
$3^{\text {rd }}$ & $34(14.9)$ \\
$4^{\text {th }}$ & $37(16.2)$ \\
$5^{\text {th }}$ & \\
Sleep & $6.93 \pm 1.431$ \\
mean $\pm S D$ & \\
Grade point average & $4.428 \pm 0.452$ \\
mean \pm SD &
\end{tabular}

Table 2 - Prevalence of internet gaming disorder in relation to gender of study subjects

\begin{tabular}{lccc}
\hline Variable & $\begin{array}{c}\text { Male } \\
(\mathbf{n}=148)\end{array}$ & $\begin{array}{c}\text { Female } \\
(\mathbf{n}=80)\end{array}$ & $\begin{array}{c}\text { Total } \\
(\mathbf{n}=\mathbf{2 2 8})\end{array}$ \\
\hline IGD & $15(10.1)$ & $5(6.3)$ & $20(8.8)$ \\
At-risk & $37(25.0)$ & $7(8.8)$ & $44(19.3)$ \\
Without IGD & $96(64.9)$ & $68(85.0)$ & $164(71.9)$ \\
\hline
\end{tabular}

Values are presented as numbers and percentages (\%). $P=0.004,95 \%$ Confidence Interval [0.05-0.13], IGD: internet gaming disorder

was the item that was most frequently answered "yes" followed by item 5 (Have you played games so that you would not have to think about annoying things?) with $35.1 \%(\mathrm{n}=80)$ answering affirmatively for item 1 and $33.3 \%(n=76)$ for item 2. Item 9 (Have you experienced serious conflicts with family, friends, or partner because of gaming?) was the item least frequently answered affirmatively with $7 \%$ answering yes. Table 3 displays the total number of affirmative responses to each item of the scale along with percentages.

Discussion. We conducted this study to estimate the prevalence of IGD among KSU students and to determine the association between IGD and gender, age, academic achievement, amount of sleep, and accommodation. In contrast to other studies, the prevalence of IGD in this study using the IGD 9-Item 
Table 3 - Distribution of responses towards the items of the scale in relation to outcome

\begin{tabular}{|c|c|c|c|c|}
\hline Items & $\begin{array}{l}\text { IGD } \\
(n=20)\end{array}$ & $\begin{array}{l}\text { Risky gamer } \\
\quad(\mathrm{n}=44)\end{array}$ & $\begin{array}{l}\text { Without IGD } \\
(n=164)\end{array}$ & $\begin{array}{c}\text { Total } \\
(\mathrm{n}=228)\end{array}$ \\
\hline Preoccupation & $19(95.0)$ & $38(86.4)$ & $23(14)$ & $80 \quad(35.1)$ \\
\hline Tolerance & $16(80.0)$ & $21(47.7)$ & $16 \quad(9.8)$ & $53(23.25)$ \\
\hline Withdrawal & $12(60.0)$ & $15(34.1)$ & $1 \quad(0.6)$ & $28 \quad(12.3)$ \\
\hline Persistence & $12(60.0)$ & $10(22.4)$ & $8 \quad(4.9)$ & $30 \quad(13.2)$ \\
\hline Escape & $15(75.0)$ & $27(61.4)$ & $34(20.7)$ & $76 \quad(33.3)$ \\
\hline Problems & $11(55.0)$ & $8 \quad(18.2)$ & $4 \quad(2.4)$ & $23 \quad(10.1)$ \\
\hline Deception & $10(50.0)$ & $15 \quad(34.1)$ & $7 \quad(4.3)$ & $32(14.0)$ \\
\hline Displacement & $14(70.0)$ & $14 \quad(31.8)$ & $0 \quad(0)$ & $28 \quad(12.3)$ \\
\hline Conflict & $9(40.0)$ & $6 \quad(13.6)$ & $1 \quad(0.6)$ & $(7.0)$ \\
\hline
\end{tabular}

Values are presented as numbers and percentages (\%). IGD: internet gaming disorder

Short Scale is $8.8 \%$, which is generally lower than results from prior studies: $9.3 \%$ among university students in Egypt and $10.9 \%$ among their medical faculty students using the short Arabic version of the IGD scale, and 9.2\% among Lebanese high school students using the IGD-20 scale. ${ }^{8,16}$ In India, a study conducted among medical and dental undergraduate students revealed a 9\% prevalence of IGD. ${ }^{17}$ However, other studies have found a lower prevalence: $5.9 \%$ amongst South Korean adolescents using a modified version of Lemmens' Game Addiction Scale for adolescents, 1.2\% among German adolescents using the Video Game Dependency Scale, and 5\% among Saudi adolescents using the Gaming Addiction Scale, which assesses similar criteria., ${ }^{78,10}$ The different scales used to assess IGD could explain the prevalence variance between studies. It is worth noting that while the Egyptian study used the same scale as this study, it also used self-rated questionnaires, their sample included students from 5 faculties besides the medical, and the majority of their sample were first-year students with a mean age of 19.6. Other studies used a different scale and targeted a different age population. ${ }^{8}$ Even though the Saudi adolescent study on gaming addiction was conducted in a different region, it revealed a lower prevalence compared to ours. The difference might be explained due to the change in parents' monitoring of gaming time and attitude as their children leave for college, as suggested by a study that found that parental monitoring could majorly inhibit IGD. ${ }^{19}$ In addition, studies have found an association between psychological distress and IGD, which could also influence the attitude of medical students towards gaming since another study using a similar population to ours has shown them to experience high levels of psychological stress. ${ }^{20,21}$ In general, the prevalence of IGD in this study is close to that found in other studies conducted in the Arab region. ${ }^{8,10,16}$

Gender had a significant association with IGD, with $10.1 \%$ of males having IGD as compared to $6.3 \%$ of females. This association also occurs in other results from Saudi Arabia which indicated a prevalence $6.4 \%$ in Saudi adolescent males and $4 \%$ in Saudi adolescent females. ${ }^{10}$ The Egyptian study revealed an IGD prevalence of $12.3 \%$ in males and $4.4 \%$ in females. ${ }^{8}$ Moreover, in Indian colleges, IGD prevalence was higher among males than females, and similar findings also resulted from a nationally representative sample in South Korea; the prevalence among males was $10.4 \%$ and $1.2 \%$ among females. ${ }^{17,7}$ One article suggests that the gaming industry's focus on targeting a male audience might be a factor that contributes to the higher vulnerability of males to develop IGD. ${ }^{22}$

In relation to age, in our sample, IGD was more prevalent among younger participants. However, we found no statistically significant association between age and IGD. Other studies have found similar results. ${ }^{7,16}$ However, in Taiwan, a study among various age groups found a significant likelihood for younger age groups to develop IGD. ${ }^{23}$ Unexpectedly, there was no statistically significant association between IGD and academic achievement. The average GPA of the IGD student group was 4.5, 4.4 among the risky gamers, and 4.4 among those without IGD. However, this can probably be attributed to the fact that $65 \%$ of the IGD group were students in their first or second year. The Saudi study among adolescents found that 38.5\% of those addicted to gaming received excellent marks, and $51.2 \%$ of the non-addicted individuals received excellent marks. ${ }^{10}$ The study from Egypt revealed that $3.3 \%$ of the individuals with IGD received excellent marks, while $5.2 \%$ of the risky gamers and $8.6 \%$ of those without IGD received excellent marks. ${ }^{8}$ In the 
Lebanese study, Lebanese students with IGD received an average of 10.5 out of 20 (B in Lebanon's school system), while the risky gamers' average was 12.3 , and $13.4(\mathrm{~B}+)$ among individuals without IGD. ${ }^{16}$ Finally, there was no significant association between the amount of sleep and IGD; the mean hours of sleep among the IGD group is 7.2, compared to the risky gamers with 6.7 and 7 hours for individuals without IGD. The lack of significance can possibly be attributed to the sample size. In Lebanon, the mean number of sleep hours for individuals with IGD was 4.9, while among risky gamers it was 6.9, with 7.1 among non-IGD individuals. ${ }^{16}$

Study limitations. This study is limited by its design being cross-sectional and was also limited to medical students at KSU. The study's findings might be difficult to generalize due to the small sample size. This study used a self-administered survey without assessing the sample clinically to validate their disordered gaming. However, the questionnaire used is validated and was used and considered acceptable by other studies. ${ }^{8}$

In conclusion, IGD is prevalent among KSU medical students, with a higher frequency among males. There was no significant association between IGD and age, sleep, academic achievement, or accommodation. Our findings emphasize the importance of further studies on and attention to IGD from the authorities regarding its risk factors and its social and academic effects in our society.

Acknowledgment. We would like to thank the College of Medicine Student Affairs Department, King Saud University, Riyadh, Kingdom of Saudi Arabia for their cooperation and assistance in providing the list of students' names; Dr. Nurah Alamro and Dr. Shatha Alduraywish for critically reviewing the study proposal; and Scribbr (www.scribbr) for English language editing.

\section{References}

1. American Psychiatric Association. Diagnostic and Statistical Manual of Mental Disorders, 5th ed. Arlington (TX): American Psychiatric Association Publishing. 2013. pp. 795-798.

2. World Health Organization. International classification of diseases for mortality and morbidity statistics. (Updated 2020. Accessed 2020 January 12). Available from URL: https://icd. who.int/browse11/l-m/en

3. Torres-Rodríguez A, Griffiths MD, Carbonell X, Oberst $\mathrm{U}$. Internet gaming disorder in adolescence: psychological characteristics of a clinical sample. J Behav Addict 2018; 7: 707-718.

4. Satghare P, Abdin E, Vaingankar JA, Chua BY, Pang S, Picco L, et al. Prevalence of sleep problems among those with internet gaming disorder in Singapore. Asian J Psychiatr 2016; 17: 188-198.

5. Stevens MW, Dorstyn D, Delfabbro PH, King DL. Global prevalence of gaming disorder: A systematic review and metaanalysis. Aust N Z J Psychiatry 2020; 1: 4867420962851.
6. Müller KW, Janikian M, Dreier M, Wölfling K, Beutel ME, Tzavara C, et al. Regular gaming behavior and internet gaming disorder in European adolescents: results from a crossnational representative survey of prevalence, predictors, and psychopathological correlates. Eur Child Adolesc Psychiatry 2015; 24: 565-574.

7. Yu H, Cho J. Prevalence of internet gaming disorder among Korean adolescents and associations with non-psychotic psychological symptoms, and physical aggression. Am J Health Behav 2016; 40: 705-716.

8. Elnahas G, Elella EA, Hewedi D, Elhabiby M, Elkholy H, Mansour O, et al. Problematic Online Gaming among a Sample of University Students in Egypt. Addict Disord Their Treat 2018; 17: 161-167.

9. Saquib N, Saquib J, Wahid A, Ahmed AA, Dhuhayr HE, Zaghloul MS, et al. Video game addiction and psychological distress among expatriate adolescents in Saudi Arabia. Addict Behav Rep 2017; 6: 112-117.

10. Rajab AM, Zaghloul MS, Enabi S, Rajab TM, Al-Khani AM, Basalah A, et al. Gaming addiction and perceived stress among Saudi adolescents. Addict Behav Rep 2020; 11: 100261.

11. Baiumy S, Elella EA, Hewedi D, Elkholy H. Internet Gaming Disorder Scale: Arabic version validation. Middle East Curr Psychiatry 2018; 25: 13-15.

12. Lemmens JS, Valkenburg PM, Gentile DA. The internet gaming disorder scale. Psychol Assess 2015; 27: 567-582.

13. Pontes HM, Griffiths MD. Portuguese validation of the Internet Gaming Disorder Scale-Short-Form. Cyberpsychol Behav Soc Netw 2016; 19: 288-893.

14. Monacis L, Palo V, Griffiths MD, Sinatra M. Validation of the Internet Gaming Disorder Scale - Short-Form (IGDS9-SF) in an Italian-speaking sample. J Behav Addict 2016; 5: 683-690.

15. Evren C, Dalbudak E, Topcu M, Kutlu N, Evren B, Pontes HM. Psychometric validation of the Turkish nine-item Internet Gaming Disorder Scale-Short Form (IGDS9-SF). Psychiatry Res 2018; 265: 349-354.

16. Hawi NS, Samaha M, Griffiths MD. Internet gaming disorder in Lebanon: relationships with age, sleep habits, and academic achievement. J Behav Addict 2018; 7: 70-78.

17. Aggarwal A, Pandian J. Internet gaming disorder in undergraduate medical and dentistry students. CHRISMED Journal Health and Research 2019; 6: 237-241.

18. Rehbein F, Kliem S, Baier D, Mößle T, Petry NM. Prevalence of Internet gaming disorder in German adolescents: diagnostic contribution of the nine DSM-5 criteria in a state-wide representative sample. Addiction 2015; 110: 842-851.

19. Bonnaire C, Phan O. Relationships between parental attitudes, family functioning and Internet gaming disorder in adolescents attending school. Psychiatry Res 2017; 255: 104-110.

20. Wu AM, Chen JH, Tong KK, Yu S, Lau JT. Prevalence and associated factors of Internet gaming disorder among community dwelling adults in Macao, China. J Behav Addict 2018; 7: 62-69.

21. Almojali AI, Almalki SA, Alothman AS, Masuadi EM, Alaqeel MK. The prevalence and association of stress with sleep quality among medical students. J Epidemiol Glob Health 2017; 7:169-174.

22. Chen KH, Oliffe JL, Kelly MT. Internet Gaming Disorder: An Emergent Health Issue for Men. Am J Men Health 2018; 12: 1151-1159.

23. Wu CY, Lee MB, Liao SC, Ko CH. A nationwide survey of the prevalence and psychosocial correlates of internet addictive disorders in Taiwan. J Formos Med Assoc 2019; 118: 514-523. 